\section{Bre 23}

COMPARATIVE INVESTIGATIONS FOR THE DETECTION OF ESTROGEN RECEPTOR PROTEIN IN BREAST CANCER TISSUE WITH $\mathrm{mABS}$

W. Eiermann, G. Matzner, M. Untch, U. Schenck, H. Hepp

The investigation was carried out on 128 breast cancer tumor specimens. One DCC-measurement was not evaluable, 12 slides in the ERICA were technically not sufficient for determination $(9.7 \%)$. Under the assumption of $10 \mathrm{fmol} / \mathrm{mg}$ protein as lower limit for receptor positive tumors there was a qualitative accordance between EIA and DCC in 78,9\%. The correlation coefficient was 0.73 . The median EIA receptor levels were slightly higher than the DCClevels. The qualitative accordance between EIA and ERICA was $60 \%$. All over receptor negative were in the EIA $38.4 \%$, in DCC $47.2 \%$ and in ERICA $60.3 \%$. EIA levels above $100 \mathrm{fmol} / \mathrm{mg}$ were nearly always combined with an positive ERICAvalue. For the weak positive ERICA values EIA receptor level was median $59 \mathrm{fmol} / \mathrm{mg}$ protein, for the positive $63 \mathrm{fmol} / \mathrm{mg}$ and for the strong positive values 126 . This indicates that the cut off point for ERICA is somewhere in the range between $50-100 \mathrm{rmol} / \mathrm{mg}$ in the EIA. In 58 patients ( 29 below the age of 50 and 29 above) the tumor probes in the DCC assay were ER-/PR+. In 17 of the 58 ER-cases EIA was able to detect ER (median level $36 \mathrm{fmol}$ ), 13 of the 17 cases were above the age of 50 . ERICA detects significantly less ER in tumor smear, that means immunocytochemical not detectable ER does not exclude hormone sensitivity of the tumor in vivo.

Frauenklinik im Klinikum Großhadern der LMU Viünchen, D-8000 München 70, Marchioninistr. 15

\section{Bre 24}

FREQUENCY DISTRIBUTION AND SIGNIFICANCE OF LYMPHORETICULAR INFILTRATES IN INVASIVE DUCTAL BREAST CANCER

H. -P. Horny and H. -A. Horst"

Cellular host defence can be divided in two basic systems: the natural resistance essentially maintained by granulocytes, natural killer cells, and especially macrophages, while $T$ lymphocytes constitute the main component of the cell-mediated immunity. We analyzed 52 invasive ductal carcinomas of the female breast not only with Giemsa staining to identify tissue mast cells, eosinophils, and plasma cells but also with a panel of monoclonal antibodies which recognize the different subsets of lymphocytes, the immune-accessory cells, the natural killer cells, and the macrophages. The study yielded the following results: 1) Most lymphoreticular cells accumulated in the surrounding and the intervening stroma, while the tumor foci generally exhibited a lower derree of infiltration. 2) Macrophages regularly made up the greatest portion of the cellular infiltrates. 3) Next in frequency were the helper/inducer cells bearing the T4 antigen, while T8 1ymphocytes generally were less frequent than the T4 cells. 4) The amount of tissue mast cells, plasma cells, and interdigitating reticulum cells varied considerably. In most cases the cell-counts were low, but tumors with a moderate or even high degree of infiltration also were encountered. 5) Natural killer cells, B lymphocytes, and eosinophils were observed only sparse thus generally constituting the smallest portion of the lymphoreticular infiltrates, while dendritic reticulum cells never could be detected.

Pathologisches Institut der Christian-Albrechts-Universität Kiel, Hospitalstr. 42, D $2300 \mathrm{Kiel}$

* II.Medizinische Klinik der Christian-Albrechts-

Universität Kiel, Metzstr. 53, D $2300 \mathrm{Kiel}$

\section{Bre 25}

CHARACTERIZATION OF LYMPHOCYTE INFTLTRATES IN BENIGN AND MALIGNANT BREAST-LESIONS J. Berling, Ch. Wittekind, S. v. Kleist, H. Gropp

Mammary carcinomas in many cases are infiltrated by Iymphocytes. We characterized the different subpopulations of infiltrating mononuclear cells in human breast tissues from 75 cancer patients and 22 patients with noncancerous breast lesions. 8 monoclonal antibodies were used on serial cryostat tissue-sections with the ABC technique. The following results were obtained: Lymphocytes were generally more frequently found and in greater quantity in malignant lesions. Cellular infiltrates consisted predominantly of T-cells, which were mainly spread throughout the stroma and which seemed to have a close contact to cancer cell-nests. The T-cell infiltration was strong or moderately strong in about $48 \%$ of the cancer tissues. T-helper/inducer cells clearly predominated in comparison to T-suppressor/cytotoxic cells in all malignant breast tissues. In contrast, the helper/suppressor ratios were well balanced in benjgn breast tissues. Only a few single NK-cells reacting with mab Leu-7 (HNK-1), were found in the stroma of the cancer tissues. However, none could be identified in non-cancerous lesions. This mab (Leu-7) also cross-reacted with epithelial cells of the breast gland ducts. A correlation of these data with the histology, the tumor stage and the significance for the clinical prognosis of the breast cancer patients is suggested. This has to be verified by a quantification of the lymphocyte infiltrates, which was tried by using a morphometric approach with an interactive registration system.

Institut für Immunbiologie der Universität, Stephan-Meier-Str. 8, D-7800 Freiburg i.Br.

\section{Bre 26}

IMMUNOHISTOLOGIC CHARACTERIZATION OF LYMPHATIC AND MONOCYTIC CELLS INFILTRATING HUMAN BREAST CANCEER

H. Denz ${ }^{1}$, M.Lechleitner ${ }^{1}$, J.Thaler ${ }^{1}$, J.Wiegele ${ }^{2}$, R.Margreiter ${ }^{2}$, 0 .Dietze ${ }^{3}$,C.Gattringer ${ }^{1}$ and H.Huber ${ }^{1}$

We studied the nature and distribution of infiltrating mononuclear cells in human breast cancer tissue using monocional antibodies and indirect immunoperoxydase techniques on frozen tissue sections. $65 \%$ of patients $(26 / 40)$ showed a moderate or extensive infiltration of lymphocytic cells, most of them being T-1ymphocytes. Generally we found a predominance of T-helper-cells, a balanced ratio or a predominance of T-suppressor-cells was seen only in cases with slight cellular infiltration. Correlating the extension of the lymphatic reaction with the presence or absence of axillary lymph node metastases no significant difference was shown between $\mathrm{N}_{0}, \mathrm{~N}_{1}$-and $\mathrm{N}_{2}-$ patients.

Furthermore we studied the monocytic infiltration. Patients without positive axillary lymph nodes showed the highest percentage of strong infiltration. Within the group exhibiting both extensive lymphocytic as well as monocytic reaction $4 / 5$ patients were nodal negative.

The extension of Iymphocytic reaction was correlated with the contents of receptors for estrogen (ER) and progesterone (PR). Patients with lower values more often showed a strong reaction than those with high ER- and PRcontents.

1) Department of Internal Medicine, University Hospital

2) Department of Surgery I, University Hospital

3) Institute for Pathology

University of Innsbruck

A-6020 INNSBRUCK, Austria 